\title{
PHARMACOVIGILANCE, DRUG INTERACTIONS, PHARMACOGENETICS AND THERAPEUTIC DRUG MONITORING OF ANTICANCER AGENTS: A VALUABLE SUPPORT FOR CLINICAL PRACTICE
}

\section{E. Raschi ${ }^{1}$, M. Del Re ${ }^{2}$, V. Conti ${ }^{3,4}$, R. Roncato ${ }^{5}$, S. Donnini ${ }^{6}$, S. Marzocco ${ }^{7}$, A. lanaro ${ }^{8}$, A. Filippelli, $i^{3,4}$ on behalf of the Cancer Pharmacology Working Group of the Italian Society of Pharmacology}

${ }^{1}$ Pharmacology Unit, Department of Medical and Surgical Sciences, Alma Mater Studiorum - University of Bologna, Bologna, Italy

${ }^{2}$ Clinical Pharmacology and Pharmacogenetics Unit, Department of Clinical and Experimental Medicine, University Hospital of Pisa, Pisa, Italy

${ }^{3}$ Department of Medicine, Surgery and Dentistry, Scuola Medica Salernitana, University of Salerno, Baronissi, Salerno, Italy

${ }^{4}$ Clinical Pharmacology and Pharmacogenetics Unit, San Giovanni di Dio e Ruggi d'Aragona University Hospital, Salerno, Italy

${ }^{5}$ Experimental \& Clinical Pharmacology Unit, Centro di Riferimento Oncologico di Aviano (CRO), IRCCS, Aviano, Italy

${ }^{6}$ Department of Life Sciences, University of Siena, Siena, Italy

${ }^{7}$ Department of Pharmacy, School of Pharmacy, University of Salerno, Fisciano, Salerno, Italy

${ }^{8}$ Department of Pharmacy, Federico II University of Naples, Naples, Italy

E-mail: vconti@unisa.it

Doi: 10.36118/pharmadvances.2021.15

\section{SUMMARY}

Clinical Pharmacology is an integral part of Oncology, especially in the modern era of precision medicine. The innovations introduced in drug development (conditional accelerated tumor-agnostic approvals through adaptive trials) and clinical practice (liquid biopsy, tumor molecular board) underline the pressing need for clinical pharmacologists, who play a catalyst and translational role in a synchronized multidisciplinary team. This review describes the latest advancements and challenges in actually implementing the precision medicine approach in oncology: pharmacovigilance, drug interactions, pharmacogenetics and therapeutic drug monitoring are often overlooked valuable tools for the understanding, detection, assessment, and prevention of adverse drug reactions, thus supporting safe prescribing in Oncology.

\section{Key words}

Therapeutic drug monitoring; cancer;

Pharmacovigilance; Pharmacogenetics; real-word data.

\section{Impact statement}

In the era of artificial intelligence and real world evidence, we strengthen the importance of clinical pharmacology as a patient-oriented discipline in Oncology.

Pharmacovigilance, Pharmacogenetics, Terapeutic Drug Monitoring are valuable tools to proactively implement precision medicine, namely prediction, prevention, detection, assessment of adverse drug reactions and clinically-important drug interactions.

Safe Prescribing in Oncology is a challenging but feasible mission for Clinical Pharmacolgists. 


\section{INTRODUCTION}

We are witnessing a paradigm shift in oncology, both in drug development and clinical practice. On one hand, the identification of new potentially targetable molecular alterations in different types of tumor leads to the development and accelerated approval of the so-called tumor-agnostic treatments, namely pembrolizumab, larotrectinib, and entrectinib (1). On the other hand, the implementation of noninvasive diagnostic tools such as liquid biopsies, and relevant search for predictive biomarkers of clinical response (e.g., circulating tumor DNA, circulating tumor cells, exosomes), are driving the concept of precision medicine in clinical practice within the institutional molecular tumor board (2).

The case of immune checkpoint inhibitors $(\mathrm{ICls})$ is noteworthy. Over the past 6 years, the Food and Drug Administration (FDA) has approved six $\mathrm{ICls}$ for more than 75 oncological indications (35 through an accelerated pathway), and the term "dangling accelerated approvals" was coined: duplicates or similar indications for which the required confirmatory trials failed to show a clear benefit, and yet their marketing authorization continued (3). Although the fact that a clinical trial failed to meet its endpoints does not necessarily mean that the drug is ineffective, in this competitive field adaptive trials have been increasingly pursued. Notably, pivotal trials have been also criticized for their "fragile" design, namely non-randomized single-arm trials testing surrogate endpoints (4-8).

In this rapidly evolving scenario, real world evidence (RWE), including data from electronic health records, claims, post-marketing safety reports, retrospective medical record reviews, and expanded access studies, has gained increased attention as a complementary source of data to traditional clinical trials (9). Although RWE was conventionally used for post-marketing surveillance, including longterm safety (and detection of rare adverse events) and effectiveness, Regulatory Agencies have demonstrated the willingness to alter the traditional regulatory paradigm and allow the use of RWE to support drug approval, thus expediting access to new therapies. A notable example was palbociclib, expanded to male patients based on data from the IQVIA insurance database, the Flatiron Health Breast Cancer Center database and the Pfizer Global Safety Database (10).

This uncertainty surrounding the dynamic risk-benefit profile of anticancer drugs in the modern era supports the proactive role of clinical pharmacology as a translational discipline, bringing together a bench-to-bedside approach, including not only laboratory (biomarkers, pharmacokinetics, genetics) and desk skills (design of clinical trials, implementation of guidelines and health technology assessment), but also hand-on clinical support to patient care (consultancy for medication review, drug-drug interactions - DDIs) (figure 1). Ultimately, a clinical pharmacologist, by contributing to the understanding of diseases, plays a key role for public health services by eventually reducing the burden of drug-related hospital admissions, especially in the oncological area (11).

The aim of this review is to describe the latest advancements and challenges in actually implementing the precision medicine approach in Oncology, focusing on the role of clinical pharmacology as an aid to support safe prescribing.

\section{TARGETED PHARMACOVIGILANCE FOR CLINICAL PRACTICE: THE EVER-CHANGING SPECTRUM OF CARDIO-ONCOLOGY}

Pharmacovigilance is becoming a holistic discipline towards safe prescribing. A proactive life-cycle risk management is the hallmark of modern pharmacovigilance, which should not be intended as a desk discipline, but rather as integrated clinical activities dealing with the detection, assessment, understanding and prevention of adverse effects or any other possible drug-related issues. For instance, clinical pharmacologists should implement 


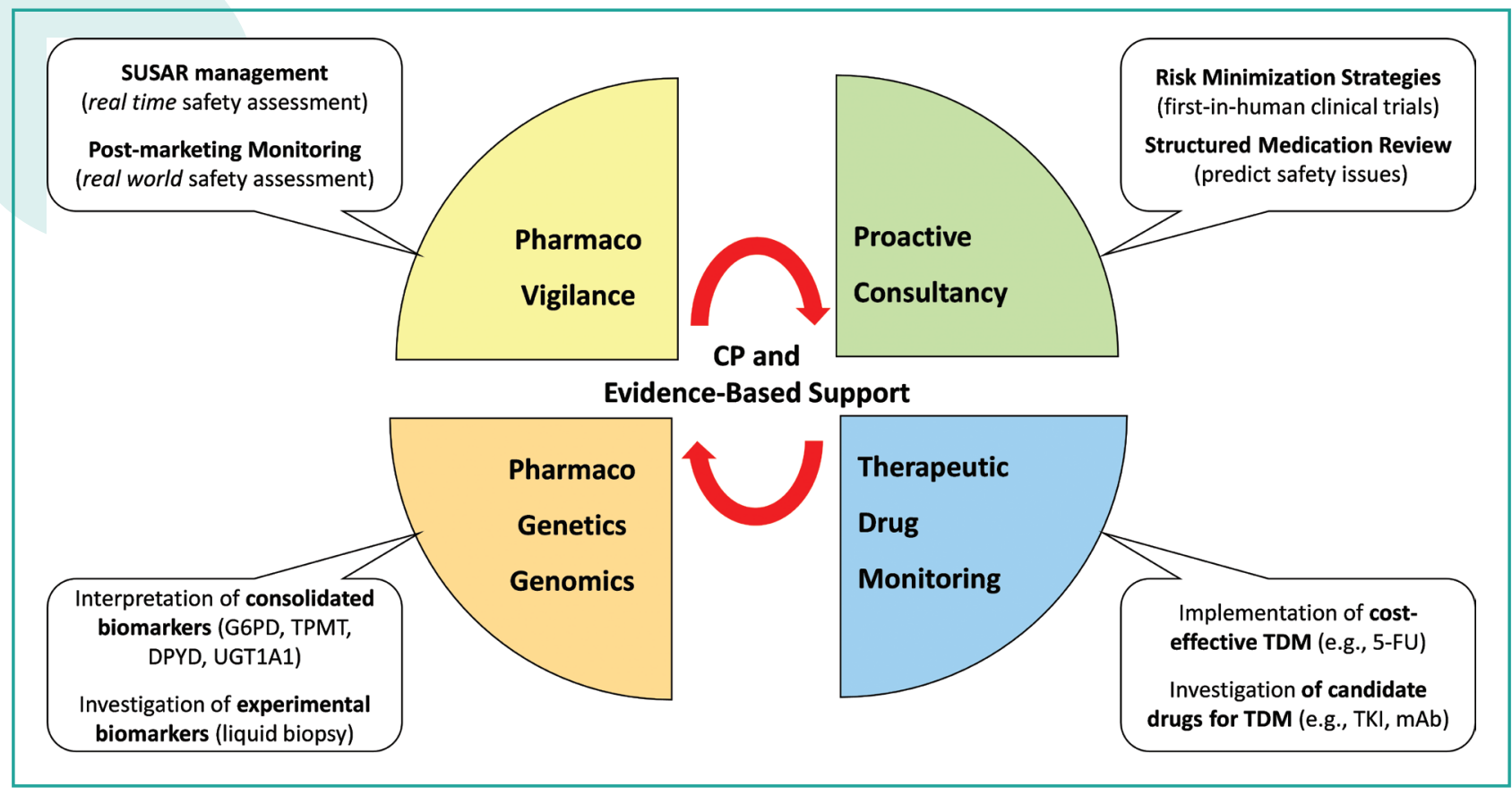

Figure 1. Key tasks of a clinical pharmacologist to support safe and personalized prescribing in Oncology.

CP: clinical pharmacologist; SUSAR: Suspected Unexpected Serious Adverse Drug Reactions; G6PD: glucose-6-phosphate dehydrogenase; TPMT: thiopurine methyltransferase; DPYD: dihydropyrimidine dehydrogenase; UGT1A1: uridine 5'-diphospho-glucuronosyltransferase; 5-FU: fluorouracil; TKI: tyrosine kinase inhibitors; mAb: monoclonal antibodies.

evidence-based personalized approaches for prevention and treatment of nausea/vomiting, neutropenia-related infections, and cancer-associated thrombosis.

In this regard, Cardio-Oncology is a recognized medical specialty and clinicians are increasingly facing the multifaceted spectrum of cardiovascular toxicities by anticancer agents, including arrhythmias (QT prolongation/Torsade de Pointes, atrial fibrillation), cardiomyopathies, vascular toxicities. The reader may refer to recent reviews for a comprehensive characterization of the cardiovascular phenotypes (12, 13). Overall, the following key messages can be derived: a) various cardiovascular damages may occur in the same patient because different drugs may impair heart function via multiple mechanisms; b) different drugs, especially targeted therapies, can cause multiple cardiovascular effects because of mechanistic overlap in the pathophysiology, whereas only a minority of agents is specifically linked to a unique form of cardiotoxicity; c) although peculiarities may exist within a given pharma- cological class, it appears that no anticancer drug is fully devoid of cardiovascular liability. This rapidly evolving spectrum of cardiovascular manifestations with targeted therapy poses new diagnostic and therapeutic challenges for oncologists and cardiologists, who must be aware of clinical pharmacology to target preventive risk minimization/stratification strategies, including medication review and critical assessment of public online tools to predict, among other, DDls $(14,15)$.

Cardiovascular toxicity with immunotherapy is an emerging clinical and research priority, and the paucity of RWE supports the need for tightening post-marketing surveillance. The case of ICls, monoclonal antibodies targeting cytotoxic-T-lymphocyte-associated antigen 4 (CTLA-4), programmed cell death 1 (PD-1) or its ligand (PD-L1), have boosted the interest in cardio-oncology. They have been especially associated with rare but potentially fatal myocarditis, typically occurring early after $\mathrm{ICl}$ initiation (median time of 2 months, with fulminant cases) (16). A recent nationwide Dan- 
ish study found a higher and long-lasting (after 6 months) absolute risk as compared to previous pharmacovigilance data, thus raising the awareness on a potential underestimated phenomenon (17). The next challenge for onco-cardiologists is represented by cardiac dysfunction with chimeric antigen receptor (CAR)-T cell and bispecific $T$ cell engager (BiTE) therapies, ranging from tachycardia, hypotension, arrhythmia, decreased left ventricular systolic function to cardiogenic shock and death. Notably, cardiac events may overlap with the so-called immune effector cell-related adverse events, including cytokine release syndrome and immune effector cell-associated neurotoxicity syndrome (18).

\section{PHARMACOVIGILANCE AS A REAL- WORLD REAL-TIME AID TO CLINICAL PRACTICE: THE CASE OF IMMUNE CHECKPOINT INHIBITORS}

Immunotherapy with $\mathrm{ICls}$ represents a paradigmatic example of how pharmacovigilance data could be exploited to proactively support appropriateness. Because of their rapid uptake and extension in different tumor types and settings, clinicians are increasingly facing off-target toxicities characterized by a unique and distinct spectrum of adverse effects, the socalled immune-related adverse events (irAEs), which can virtually affect any organ or system in the body (19). Regularly updated guidelines offer a compendium of irAEs and discuss both clinical presentation and management. Of note, the pathophysiology of organ-specific irAEs can differ (antibody-mediated bullous pemphigoid vs cytotoxic T-cell-mediated myocarditis), many patients present with multisystem refractory toxicities, and the use of systemic corticosteroids and immunosuppression is challenging (potential detrimental effect on $\mathrm{ICl}$ efficacy), thus warranting new skills and a multidisciplinary team comprising clinical pharmacologists (20).

Although most common irAEs were identified during preapproval clinical development, their assessment and clinical characterization in terms of spectrum, timing and outcomes were only recently investigated through real-world, large-scale pharmacovigilance analyses (21). Specifically, the Food and Drug Administration Adverse Event Reporting System (FAERS) and the worldwide Vigibase have attracted considerable interest among oncologists. These international spontaneous reporting databases represent an unprecedented opportunity to provide oncologists with major and novel unexpected toxicities, thus informing clinical practice for proactive monitoring (e.g., early assessment of liver function for drugs with similar pharmacodynamics) (22). Of note, these archives can be queried through online tools (e.g., FAERS public dashboard) by individual researchers, or raw data can be accessed/ downloaded for customized analyses, namely disproportionality algorithms aimed at detecting higher-than-expected reporting of a given adverse event, also known as a 'signal'.

Of note, the accuracy of these pharmacovigilance analyses is remarkable (i.e., the ability to distinguish between true and false negatives), and a recent study found that risk estimates from meta-analyses and pharmacovigilance analyses were correlated in some cases (23). The following emerging roles of pharmacovigilance studies can be identified: a) characterization of adverse events of special interest (e.g., interstitial lung disease, venous thromboembolism), also in terms of clinical features; b) explore the underlying pharmacological bases, including potential correlation with pharmacokinetic features (e.g., lipophilicity and liver injury) and receptor affinity (VEGFR and hypertension); c) early detection or rare, unexpected, late-onset and long-lasting adverse events (including those from DDIs), which cannot be fully appreciated in pivotal trials. When properly designed (taking into account limitations), these hypothesis-generating studies provide the rationale to carefully design prospective cohort studies and pragmatic clinical trials (24).

Therefore, it is not surprising that immunotherapy, especially $\mathrm{ICls}$, represented a privileged 
setting to perform pharmacovigilance studies: as of February 2020, 30 real-world post-marketing studies on $\mathrm{ICl}$ safety were published (21). As of May $5^{\text {th }}, 2021$, the same search yielded 48 additional pharmacovigilance studies, thus demonstrating an ongoing fervent area of research supplementary material. Key findings are summarized in table I. This plethora of studies open new avenues to conduct next-generation real world studies aimed at: a) assessing comparative safety of $\mathrm{ICls}$ (i.e. head-to-head comparisons), b) investigating safe rechallenge (and the therapeutic impact of switching among $(\mathrm{Cls}), \mathrm{c})$ unraveling predictivity of irAEs as real biomarkers of effectiveness. The emerging uses of $\mathrm{ICls}$ in combination regimens (e.g., anti-angiogenic drugs), with potential toxic synergy, strengthen the need for pharmacovigilance in exploring complex pharmacodynamic interactions.

Pharmacovigilance is also an integral part of regulatory pharmacology, namely safety surveillance within clinical trials to detect Suspected Unexpected Serious Adverse Drug Reactions (SUSARs). Determining whether an adverse reaction is a SUSAR is a matter to clinical pharmacologists, who should combine medical considerations (e.g., alternative causes) with pharmacological assessment (e.g., plausibility in terms of time to onset and relevant mechanism). A recent French experience pooled data from academic sponsors and proposed SUSARs as a source of signals, especially for anticancer drugs (25). In this perspective,

Table I. Key features of irAEs with ICls emerged from pharmacovigilance studies.

\begin{tabular}{|c|c|}
\hline Feature & Comment/notes \\
\hline Spectrum & $\begin{array}{l}\text { Gastrointestinal disorders, hypophysitis, adrenal insufficiency, hypopituitarism and } \\
\text { skin disorders were more frequently reported with anti-CTLA-4 drugs. } \\
\text { Thyroid dysfunction, pneumonitis and cholangitis were more frequent with anti- } \\
\text { PD-1/PD-L1 agents. }\end{array}$ \\
\hline Kinetic (latency) & $\begin{array}{l}\text { Median time to onset was } 46 \text { days, with earlier occurrence for combination } \\
\text { regimens, as compared to monotherapies, especially in the case of fatality. } \\
\text { Late-onset and long-lasting irAEs have been also described. }\end{array}$ \\
\hline Frequency & $\begin{array}{l}\text { Endocrine irAEs (especially hypothyroidism) appear the most frequent, as compared } \\
\text { to myocarditis, myositis and neurological irAEs. } \\
\text { Rare previously unknown irAEs have been recently observed (bone fracture, } \\
\text { hepatitis B reactivation, CRS, GVHD). }\end{array}$ \\
\hline Fatality proportion & $\begin{array}{l}\text { The median fatality proportion was } 20 \% \text {, but ranged considerably across irAEs: } \\
\text { from hyperthyroidism and hypothyroidism }(<1 \%) \text { to myocarditis (up to } 60 \% \text { when } \\
\text { co-occurring with myositis and myasthenia gravis). }\end{array}$ \\
\hline Predictors & $\begin{array}{l}\text { Multisystem irAEs have been described; debated potential correlation with efficacy } \\
\text { and tumor mutational burden have been observed. } \\
\text { No significant sex-associated differences in irAEs. } \\
\text { Younger age was associated with a similar rate of any irAEs, but more frequent } \\
\text { severe irAEs and more hospitalizations. } \\
\text { Colitis and hepatitis were more common in younger patients, whereas myocarditis } \\
\text { and pneumonitis had an older age distribution (more deaths and increased length } \\
\text { of stay when elderly are hospitalized. }\end{array}$ \\
\hline Rechallenge & $\begin{array}{l}\text { Positive rechallenge in } 29 \% \text { (recurrence of the same irAE after a rechallenge with } \\
\text { the same } \mathrm{ICI} \text {, previously discontinued). } \\
\text { Colitis, hepatitis and pneumonitis were associated with a higher recurrence rate. }\end{array}$ \\
\hline $\begin{array}{l}\text { Pharmacodynamics } \\
\text { interactions }\end{array}$ & $\begin{array}{l}\text { No interaction with influenza vaccination in terms of cardiovascular irAEs. } \\
\text { Possible increased occurrence of pneumonitis with EGFR inhibitors. }\end{array}$ \\
\hline
\end{tabular}

CTLA-4: cytotoxic T-lymphocyte-associated protein 4; PD-L1: Programmed death-ligand 1; irAEs: immune-related adverse events; CRS: cytokine release syndrome; GVHD: graft versus host disease. 
the information arising from SUSARs, if communicated in real time to clinicians, could help in preventing and mitigating drug-related risks, or in monitoring the risk of adverse reactions for drug(s) with similar mechanism of action.

\section{DRUG INTERACTIONS: EMERGING CLUES}

Nowadays, the life expectancy of cancer patients has significantly increased (26). This undoubtedly represents a huge achievement but, at the same time, has led to a rising number of people affected by comorbidities that it becomes practically a rule in elderly patients (27). Almost inevitably, comorbidities imply the need for polypharmacy (28), which may have negative clinical consequences. These include further pathological conditions and adverse drug reactions (ADR) due to DDIs (29). Nearly $20-30 \%$ of ADR have been reported as associated with DDIs, of which $1-2 \%$ are life-threatening while a considerable percentage (nearly $70 \%$ ) are clinically relevant $A D R$, needing intervention (30).

DDls can occur via both pharmacodynamic and pharmacokinetic mechanisms, leading to toxicity or treatment failure (31). Several DDIs arise during drugs metabolism, commonly involving inhibition or induction of the CYP450 isoenzymes (32). However, they can often derive from changes in the levels of transport proteins, including Breast Cancer Resistance Protein (BCRP), Uridine diphosphate-glucuronosyltransferase (UGT), and P-glycoprotein (P-gp) (33).

A valid example in the oncologic area is that between brivudine, an antiviral drug used in the treatment of herpes zoster, and fluoropyrimidines (FP) such as 5-fluorouracil (5-FU). Brivudine irreversibly inhibits the enzyme dihydropyrimidine dehydrogenase (DPD), which, as discussed in the following paragraph, represents the rate-limiting step of the FP catabolism $(34,35)$. The Italian Regulatory Agency (AIFA) issued a dedicated warning advising against brivudine-FP co-administration be- cause of the risk of the anticancer drug accumulation and recommended to administer the FP-based therapy only 4 weeks after completion of the antiviral treatment (36).

Most cancer patients develop multiple comorbidities, leading to polypharmacy and consequently the risk of DDls, which exponentially increases with the number of drugs administered, thus underlying the critical importance of pharmacovigilance (37). Unfortunately, DDIs are not yet routinely checked in the clinical practice. In 2015, an interesting prospective study was designed to identify DDIs requiring clinical interventions in oncological patients initiating a new anticancer therapy (38). A total of 302 patients were included in the study, the majority of them (87\%) were suffering from a solid malignancy. Although with a large range (1-25), the median number of pharmacological agents administered was high $(n=10)$. A considerable number (120/603) of the DDIs identified in 81 patients resulted in a clinical intervention as reported by the oncologists who took part in this survey. Importantly, in 42/81 cases, a need of an extra intervention was recommended by a clinical pharmacologist.

The clinically relevant DDIs involved a wide range of drug classes but the most frequently reported occur with oral anticoagulants, nonsteroidal anti-inflammatory drugs (NSAIDs) and corticosteroids but also with antiepileptics and antimicrobials (table II). Pharmacodynamic DDls may also occur and can cause QT prolongation, gastrointestinal toxicity and central nervous system depression. Notably, among the anticancer agents, cytotoxic ones were the absolute protagonists but some DDls occurred in patients taking tyrosine kinase inhibitors (TKIs) and monoclonal antibodies (mABs) and also a combination of anticancer drugs and/or radiotherapy (38).

Another concern emerged from the study by van Leeuwen et al. was the large percentage (81\%) of patients using at least one over-thecounter (OTC) drug. This represents a crucial issue given the high frequency of use of OTC drugs and complementary and alternative 
Table II. Examples of clinically important drug-drug interactions (DDIs) in oncology. Data have been derived from https://www.cancer-druginteractions.org/checker, https://www.drugs.com/drug_interactions.html, https:// intercheckweb.marionegri.it/.

\begin{tabular}{|c|c|c|c|c|}
\hline DDls & $\begin{array}{l}\text { Pharmacological } \\
\text { mechanism }\end{array}$ & Clinical effect & $\begin{array}{l}\text { Clinical relevance } \\
\text { (quality of } \\
\text { evidence)\# }\end{array}$ & Recommendation \\
\hline $\begin{array}{l}\text { NSAIDs- } \\
\text { Methotrexate }\end{array}$ & $\begin{array}{l}\text { PK (reduced renal } \\
\text { clearance and possible } \\
\text { albumin displacement } \\
\text { by NSAIDs) }\end{array}$ & $\begin{array}{l}\text { Increased toxicity } \\
\text { of methotrexate } \\
\text { (stomatitis, acute renal } \\
\text { failure, pancytopenia) }\end{array}$ & $\begin{array}{l}\text { MAJOR } \\
\text { (intermediate) }\end{array}$ & $\begin{array}{l}\text { Avoid NSAIDs (paracetamol } \\
\text { as alternative as pain killer) }\end{array}$ \\
\hline $\begin{array}{l}\text { Simvastatin- } \\
\text { Imatinib }\end{array}$ & $\begin{array}{l}\text { PK (CYP3A4 inhibition } \\
\text { by imatinib) }\end{array}$ & $\begin{array}{l}\text { Increased toxicity } \\
\text { of simvastatin } \\
\text { (myotoxicity and/or } \\
\text { liver injury) }\end{array}$ & MAJOR (low) & $\begin{array}{l}\text { Consider alternatives } \\
\text { to simvastatin (pravastatin } \\
\text { or rosuvastatin) }\end{array}$ \\
\hline $\begin{array}{l}\text { Nivolumab- } \\
\text { dexamethasone }\end{array}$ & $\begin{array}{l}\text { PD } \\
\text { (immunosuppression } \\
\text { by dexamethasone) }\end{array}$ & $\begin{array}{l}\text { Reduced efficacy } \\
\text { of nivolumab }\end{array}$ & $\begin{array}{l}\text { CONTRAINDICATED } \\
\text { (very low) }\end{array}$ & $\begin{array}{l}\text { Use of systemic corticosteroids } \\
\text { and other immunosuppressants } \\
\text { at baseline, before starting } \\
\text { nivolumab, should be avoided. } \\
\text { However, they can be used to treat } \\
\text { irAEs with nivolumab }\end{array}$ \\
\hline $\begin{array}{l}\text { Enzalutamide- } \\
\text { Rivaroxaban }\end{array}$ & $\begin{array}{l}\text { PK (induction } \\
\text { of CYP3A4 and } \\
\text { inhibitor of P-gp } \\
\text { in vitro } \\
\text { by enzalutamide) }\end{array}$ & $\begin{array}{l}\text { Unpredictable } \\
\text { outcome, with } \\
\text { potential increased } \\
\text { rivaroxaban toxicity } \\
\text { (bleeding) }\end{array}$ & $\begin{array}{l}\text { CONTRAINDICATED } \\
\text { (very low) }\end{array}$ & $\begin{array}{l}\text { Consider alternatives } \\
\text { to rivaroxaban (dabigatran } \\
\text { or edoxaban), and monitor }\end{array}$ \\
\hline $\begin{array}{l}\text { Ketoconazole- } \\
\text { Irinotecan }\end{array}$ & $\begin{array}{l}\text { PK (CYP3A4 inhibition } \\
\text { by ketoconazole); SN- } \\
38 \text { exposure increased } \\
\text { by approximately } \\
100 \%\end{array}$ & $\begin{array}{l}\text { Increased toxicity } \\
\text { of irinotecan/SN-38 } \\
\text { (e.g., diarrhea and } \\
\text { hematological toxicity } \\
\text { by irinotecan) }\end{array}$ & $\begin{array}{l}\text { CONTRAINDICATED } \\
\text { (low) }\end{array}$ & $\begin{array}{l}1 \text { week washout of ketoconazole } \\
\text { Dose reduction of irinotecan } \\
\text { (consider genotyping) } \\
\text { TDM (if available) } \\
\text { Consider alternatives to } \\
\text { ketoconazole (e.g., fluconazole) }\end{array}$ \\
\hline Erlotinib-PPIs & $\begin{array}{l}\text { PK (decreased } \\
\text { exposure to erlotinib } \\
\text { due to the prolonged } \\
\text { effect of PPIs } \\
\text { on gastric pH) }\end{array}$ & Reduced efficacy & $\begin{array}{l}\text { CONTRAINDICATED } \\
\text { (low) }\end{array}$ & $\begin{array}{l}\text { Potential class effect with all TKIs } \\
\text { (except for osimertinib) } \\
\text { Assess appropriate use of PPIs } \\
\text { Consider staggered administration }\end{array}$ \\
\hline $\begin{array}{l}\text { Ribociclib- } \\
\text { Amiodarone }\end{array}$ & $\begin{array}{l}\text { PK (inhibition } \\
\text { of CYP3A4 by } \\
\text { ribociclib) and PD } \\
\text { (hERG blockade) }\end{array}$ & $\begin{array}{l}\text { Increased synergistic } \\
\text { toxicity (QT } \\
\text { prolongation and TdP } \\
\text { occurrence*) }\end{array}$ & $\begin{array}{l}\text { CONTRAINDICATED } \\
\text { (low) }\end{array}$ & $\begin{array}{l}\text { ECG monitoring and correction } \\
\text { of risk factors (e.g., hypokalemia)* } \\
\text { Caution also with alternatives } \\
\text { to ribociclib (palbociclib and } \\
\text { abemaciclib) }\end{array}$ \\
\hline $\begin{array}{l}\text { Brivudine-5- } \\
\text { Fluorouracil }\end{array}$ & $\begin{array}{l}\text { PK (DPD inhibition } \\
\text { by brivudine) }\end{array}$ & $\begin{array}{l}\text { Increased toxicity } \\
\text { of 5-fluorouracil } \\
\text { (myelotoxicity, nausea, } \\
\text { vomiting, diarrhea, } \\
\text { stomatitis, skin } \\
\text { toxicity) }\end{array}$ & $\begin{array}{l}\text { CONTRAINDICATED } \\
\text { (low) }\end{array}$ & $\begin{array}{l}4 \text { weeks of brivudine washout, } \\
\text { clinical monitoring } \\
\text { Consider DPD genotyping }\end{array}$ \\
\hline $\begin{array}{l}\text { Carbamazepine- } \\
\text { Imatinib }\end{array}$ & $\begin{array}{l}\text { PK (CYP3A induction } \\
\text { by carbamazepine) }\end{array}$ & $\begin{array}{l}\text { Reduced efficacy } \\
\text { of imatinib }\end{array}$ & $\begin{array}{l}\text { CONTRAINDICATED } \\
\text { (intermediate) }\end{array}$ & $\begin{array}{l}50 \% \text { increase of imatinib dosage } \\
\text { TDM should be considered (if } \\
\text { available) }\end{array}$ \\
\hline $\begin{array}{l}\text { Tamoxifene- } \\
\text { Paroxetine }\end{array}$ & $\begin{array}{l}\text { PK (CYP2D6 inhibition } \\
\text { by paroxetine) and PD } \\
\text { (hERG blockade) }\end{array}$ & $\begin{array}{l}\text { Reduced efficacy } \\
\text { of tamoxifene and } \\
\text { increased synergistic } \\
\text { toxicity (QT } \\
\text { prolongation and TdP } \\
\text { occurrence*) }\end{array}$ & $\begin{array}{l}\text { CONTRAINDICATED } \\
\text { (high) }\end{array}$ & $\begin{array}{l}\text { Consider alternatives to paroxetine } \\
\text { (citalopram, venlafaxine) } \\
\text { ECG monitoring and correction } \\
\text { of risk factors (e.g., hypokalemia)* }\end{array}$ \\
\hline
\end{tabular}

\# Clinical Relevance was graded as follows: CONTRAINDICATED: avoid co-administration, or tight monitoring (clinical or TDM); MAJOR: serious but manageable event (e.g., dose reduction). Quality of evidence was graded as follows: Very low: in vitro study; low: data in healthy volunteers or extrapolated from similar drugs; intermediate: well documented case report/case series; high: well documented observational studies; top: randomized clinical trials, systematic reviews.

ECG: electrocardiogram; hERG: human Ether-à-go-go-Related Gene (potassium channel); PK: pharmacokinetic; PD: pharmacodynamic; PPIs: proton pump inhibitors; NSAIDs: non-steroidal anti-inflammatory drugs; TDM: therapeutic drug monitoring; TdP: torsade de pointes.

* See crediblemeds.org for details. 
medicine (CAM) in oncology $(39,40)$. Notably, 21 herbs, food and dietary supplements were found to significantly modify cytochromes' activity, a major metabolic pathway for many anticancer drugs, thus potentially causing treatment failures or toxicities (41). Therefore, (hemato)oncologists and clinical pharmacologists should consider potential DDls involving both cytotoxic and biologics compounds without forgetting the role played by CAM that have been often recognized as spreaders of dangerous but potentially predictable adverse events.

In the last years, relevant advancements were made especially regarding methods (e.g. mass spectrometry) to quantify concentrations of multiple drugs and their metabolites in human plasma $(42,43)$. Besides the possibility to measure and monitor patients' drug exposure, such techniques allow us to better characterize the expression and function of all molecules (e.g. enzymes and protein transporters) involving in the DDls.

An emerging unsettled issue in DDls regards the complex interactions between drugs and the microbiome. Apart from the well-known influence of gut microbes on delayed diarrhea by irinotecan, recent data also pointed out the impact of the gut microbiome on $\mathrm{ICl}$ pharmacodynamics, especially in terms of efficacy (44). Therefore, questions arise on the potential effect of other dysbiosis-inducing drugs such as antibiotics and proton pump inhibitors (PPIs). The multifaceted impact of PPIs, including influence on the bioavailability of oral TKIs, requires extensive investigation. Meanwhile, healthcare professionals should limit unnecessary overuse of PPIs (45).

As a final note, oncologists should be reminded on the importance of critically reading the summary of product characteristics and publicly available online tools on the risk of DDIs, including cancer-druginteractions.org, offering public access to user-friendly, drug interaction charts and crediblemeds.org/oncosupport, providing a printable list of QT-prolonging drugs that are prescribed in oncology, includ- ing anticancer agents, antiemetics, antidepressants, and anesthetics, with relevant categorization for torsadogenic liability (15).

\section{PHARMACOGENETICS TO PERSONALIZE DRUG TREATMENT IN CANCER PATIENTS: CURRENT STATUS} Pharmacogenetics (PGX) implementation in clinical practice is steadily increasing. The term pharmacogenetics relates to drug response based on genetic influences, and the PGx focuses on drug-gene interactions, dealing with the influence of inherited genetic variants (gene expression or single-nucleotide polymorphisms, SNPs) on drug response (pharmacokinetics and pharmacodynamics, PK/ PD) (46). The challenge of PGx is to optimize and personalize drug therapy, with respect to the patients' genotype, to ensure maximum efficiency with minimal adverse drug reactions (47).

The detection of hereditary variance in genes coding for proteins affecting PK/PD of drugs can dramatically decrease the rate of side effects in many cancer drugs. In cancer treatment, even though experts differ in the interpretation of PGx testing and their recommendations, genetic deregulations affecting genes coding for DPD, UGT1A1, TPMT, and CYP2D6 are now considered as critical issues for patients treated with 5-FU/capecitabine/ tegafur, irinotecan, mercaptopurine/azathioprine and tamoxifen, respectively (48). Currently, the pharmacogenetic tests acknowledged for their clinical value in preventing FP and irinotecan-related toxicities, include the dihydropyrimidine dehydrogenase (DPYD) and UDP glucuronosyl transferase family 1 member A1 (UGT1A1) genes, encoding for DPD and UGT1A1 proteins, respectively.

FP (5-FU and its prodrugs capecitabine and tegafur) are chemotherapeutics used for the treatment of a variety of solid malignancies alone or in combination with several other pharmacological agents. Their use is correlated with severe toxicities: up to $9 \%$ of the pop- 
ulation is known to have a decreased enzyme activity and $0.5 \%$ of Caucasian patients are at risk to experience FP-related lethal toxicity $(49,50)$. The antiproliferative activity of FP depends on the equilibrium between anabolic and catabolic pathways. Indeed, more than $80 \%$ of the administered dose of $5-\mathrm{FU}$ is transformed to inactive metabolites, and only the remaining $20 \%$ or less is responsible for the therapeutic effect. The first step of 5-FU catabolism depends on DPD enzyme. More than 90 SNPs and deletions have been identified within DPYD, and for some of these mutations, related to reduced enzyme activity, the association with FP toxicity has been clearly demonstrated (51-53). It has been acknowledged that DPYD*2A, DPYD*13, and DPYDHapB3 and DPYD-2846 increase the risk of developing a severe early adverse event after FP treatment, and pre-emptive genotyping has been recommended by international guidelines to increase chemotherapy safety. Due to a large amount of published data and clinical evidence, the DPD pharmacogenetic test is frequently applied prior to FP treatment. In particular, the EMA in 2020 stated that FP are contraindicated in the case of patients with DPD 0 activity, and dose adjustment can be considered in case of partial activity; while genotyping is recommended prior to the treatment with 5-FU or with the related medicines, capecitabine and tegafur (54). The Italian Association of Medical Oncology (AIOM) in collaboration with the Italian Society of Pharmacology (SIF) in 2018 published the first recommendation on DPYD genotyping in clinical practice for FP therapy, updated in 2020 (55), as well as the Clinical Pharmacogenetics Implementation Consortium (56), and the Dutch Pharmacogenetics Working Group (57). The aforementioned organizations recommend avoiding FP for patients with homozygous variants for $D P Y D * 2 A, D P Y D * 13$, and DPYD-2846; a 50\% reduction in heterozygous patients for DPY$D * 2 A$, DPYD*13, and DPYD-2846; and a 50\% or $25 \%$ in patients homozygous or heterozygous for DPYDHapB3, respectively.
Irinotecan is a topoisomerase I inhibitor used in the therapeutic protocols of colorectal cancer. It is a prodrug converted into its active metabolite 7-ethyl-10-hydroxycamptothecin (SN-38) via carboxylesterases. Exposure to the $\mathrm{SN}-38$ is the major cause of irinotecan-related adverse events, with severe neutropenia and delayed diarrhea as the dose-limiting toxicities (58). SN-38 is among the substrates deactivated by UGT1A1 into SN-38-glucuronide. There are more than 113 UGT1A1 gene variants described in the literature that can affect the enzymatic activity of UGT1A1 (58). Some of these variants impair the activity of the UGT1A1 enzyme resulting in an increased level of $\mathrm{SN}-38$, and in turn, in severe toxicities. UGT1A $1 * 28$ is a gene variant with poor metabolizer phenotype whose frequency is different according to the population, for instance, in Asians: 0.090.16 , in Caucasians: $0.26-0.31$ and in AfricanAmericans: $0.42-0.56$ (59). UGT1A $1 * 28$ genotyping is recommended prior to irinotecan administration. In the current clinical practice, there are available guidelines published from the Dutch and the French working groups (60). Similarly, AIOM and SIF in 2018 published the first recommendation on UGT1A1 genotyping in clinical practice for irinotecan therapy, updated in 2020 (61). Although there are some differences among the guidelines, they all recommended a reduction of the irinotecan dose by $30 \%$ in patients homozygous for the UGT1A1*28 risk allele (*28/*28). The FDA, EMA, Swissmedic and Health Canada approved drug labels contain PGx information that recommends a reduced starting dose for homozygous UGT1A1*28 patients.

Several reasons are slowing down the implementation process of PGx in cancer medical centers, including the unavailability of comprehensive and clear guidelines and the lack of formal health technology assessment studies. Currently, there are guidelines available for 11 cancer drugs only. Further, there are several discrepancies in guidelines published by different organizations for the same drug, both in the recommendation and in the phe- 
notype-genotype translation. Consequently, the information provided in the label may differ among Countries, thus further confusing clinicians and hindering the PGx implementation process.

To overcome the lack of formal health technology assessment studies several ongoing projects have been set up around the world to test the implementation process of $P G x$ in clinical practice. Among these, is the U-PGx (Ubiquitous Pharmacogenomics) (62) program, which was launched January 1, 2016, in Europe with the financial support of the Horizon 2020 granting program, under the coordination of Leiden University Medical Center. U-PGx aims to "make effective treatment optimization accessible to every European citizen" (63) and involves 15 research centers in 10 European countries. Through a large randomized clinical trial in seven different health care centers U-PGx aims to test the clinical value and utility of PGx implementation into clinical practice.

\section{THE CURRENT ROLE OF THERAPEUTIC DRUG MONITORING IN ONCOLOGY: FROM TKIS TO IMMUNOTHERAPY}

The more recent anticancer drugs are based on oral administration and if this aspect is associated with a better quality of life for patients it also generates a complex effect in drugs pharmacokinetic. Interindividual pharmacokinetics variability is influenced not only by the genetic heterogeneity of drug targets but also by the pharmacogenetic background of the patient and by the treatment adherence as well as by environmental factors (e.g. drug-drug/drug-food interactions). Thus, the increasing use of targeted agents is producing new paradigms in cancer care, with drug adherence becoming a more critical issue associated to the increased use of oral cancer drugs. Thus, the management of oncology patients requires the development and attention to innovative approaches for cancer treatment individualization and monitoring (64).
Oral targeted drugs are licensed for use at fixed doses, with adjustment on an individual basis in cases of insufficient response or substantial toxic effects. In this context, considering the narrow therapeutic index and proven PK/PD (toxicity-antitumor activity) relationships for many anticancer drugs, therapeutic drug monitoring (TDM) can provide a good support for cancer therapy optimization by adapting drug dose and/or schedule, and favoring adherence to ultimately improve efficacy and/or reduce toxicity (65-67).

Currently, only for imatinib were concentration thresholds proposed. In particular, the European Society for Medical Oncology suggests that «measuring imatinib blood concentrations may be important in all patients and is recommended in case of sub-optimal response, failure, dose-limiting toxicity or adverse events» (68). Recent evidence improved our understanding of the relationship between TKI exposure and clinical outcome, but the exact plasma threshold for clinical benefit remains to be investigated (69). Levels of evidence for TDM are however heterogeneous among TKls: appropriate blood levels need to be prospectively evaluated in various patient subgroups, both minimal and maximal levels (65-67). With the current state of knowledge, applications for TDM with oral targeted therapies may best be reserved for individual situations relating to a lack of therapeutic response, severe or unexpected toxicities, DDIs or doubts about adherence to treatment (70). However, the use of TDM should be regularly considered before these critical situations patients, with particular attention to specific populations (e.g. geriatric patients, paediatrics, sarcopenic or obese patients and patients with impaired hepatic or renal function). Despite the fact that pharmacokinetic exposure of TK is highly variable and clear relationships exist between exposure and treatment outcomes, fixed dosing is still standard practice (71). TDM logistical issues often limit the introduction of personalized dosing. Targets used for TDM are based on plasma ex- 
posure that is measured as AUC (area under the concentration-time curve) or as trough concentration (Ctrough) defined as the concentration measured immediately before the new dose of drug administration. This specific time point, as the target for TDM, affects the logistic organization for this practice. The TDM for Recently, Ruben and coworkers reported that plasma concentrations of some small molecule kinase inhibitors (SMKIs) observed during $24 \mathrm{~h}$ blood sampling were used for extrapolation to trough levels. In total 2241 blood samples were analyzed. The estimated Ctrough levels of afatinib and sunitinib fulfilled the equivalence criteria if the samples were drawn after Tmax. The calculated Ctrough levels of erlotinib, imatinib and sorafenib met the equivalence criteria if they were taken, respectively, $12 \mathrm{~h}, 3 \mathrm{~h}$ and $10 \mathrm{~h}$ after drug intake. For regorafenib extrapolation was not feasible. Thus, extrapolation of randomly taken drug concentrations to a trough concentration using the mean elimination half-life is feasible for multiple SMKIs. Therefore, this method could contribute to the implementation of TDM in oncology (72). The introduction of cancer immunotherapy has improved the prognosis of several malignancies especially melanoma and non-small cell lung cancer $(73,74)$. The forefront of such a targeted approach is represented by ICls, which are effective in restoring the anti-tumor immune response, while increasing the occurrence of irAEs (75). It is important to consider that only $20-40 \%$ of patients treated with $\mathrm{ICls}$ have good responses showing long-lasting survival. Nevertheless, insufficient attention has been deserved to personalization and optimization of the ICls-based therapy (76). One of the reasons for the limited effectiveness of the immunotherapy is related to the quite complex PK/PD relationship and large interindividual variability in PK parameters of $\mathrm{ICls}$. Several factors, including body weight, serum albumin levels, the presence of antidrug antibodies (ADAs), tumor microenvironment and tumor burden and the heterogeneous expres- sion of the immune checkpoint molecules within the tumors influence such parameters and, as a result, they can affect clinical outcomes of the treated patients $(77,78)$.

Immunotherapy, by acting via the immune system, represents a unique treatment as compared to other anticancer therapies. In particular, in the case of $\mathrm{ICls}$, it is difficult to determine the exposure-efficacy and exposure-toxicity relationship because they are not direct or proportional to the dosage (79).

Currently, data on the potential of TDM to optimize immunotherapies are scarce and inconclusive. It has been observed that pembrolizumab exposure is not correlated with response rate (79). Similarly, Wang et al., investigating nivolumab-related exposure-response in advanced melanoma, failed to find a correlation between drug concentrations measured over time and response rate or toxicity (80).

Conversely, three studies enrolling a total of 419 patients with advanced melanoma receiving ipilimumab in a range dosage of 0.3$10 \mathrm{mg} / \mathrm{kg}$ have demonstrated that minimum concentration at steady state $\left(C_{\text {min,Ss }}\right)$ more than the dosage represents a useful predictor of both a clinically important response and, importantly, of irAEs, thus also raising the hypothesis that irAEs are actual biomarkers of efficacy (81).

Nowadays, analytical methods to detect and quantify $\mathrm{ICls}$ in human plasma have been developed and validated providing the basis to perform a TDM of such treatments $(82,83)$. Monitoring $\mathrm{ICl}$ concentrations could be also evaluated with the perspective of potentially postponing infusion, considering that several $\mathrm{ICls}$ were approved as a flat dose (84). Therefore, there is an urgent need to perform studies testing PK and PD biomarkers in order to guide dose personalization of these drugs.

\section{CONCLUSIONS AND PERSPECTIVE}

Shifting from blockbuster medicine to precision medicine in the mid-2000s has been a 
major advance in oncology, and a growing number of anticancer drugs were approved with a companion or complementary diagnostic test intended to identify patients who may optimally respond (85). However, achieving optimal response, while minimizing expected toxicities, requires careful understanding of dose-exposure relationship and relevant factors of variability (86). Although there is emerging evidence to routinely adopt PK/PD modeling, TDM, PGx and Pharmacovigilance on a large scale, there are also rooms for improvement actual feasibility, acceptance and implementation in real world clinical care.

Most emerging public-private initiatives are directed towards Artificial Intelligence, both at the pre-clinical and clinical level, and a concerted effort by variegate Stakeholders was recently promoted by the so-called "Mission Cancer" of Horizon Europe, which proposes a Europe-wide platform utilizing existing research infrastructures and investing in the development of models and new technologies to better understand cancer, thus fulfilling patients' expectations. The emergence of "big data" characterized by massive volume, complexity and velocity has presented an intriguing opportunity for the study of digital healthcare, and artificial intelligence (Al) such as machine learning have attracted interest of researchers and regulators. In fact, there are several sources of real world evidence (RWE), including spontaneous reporting systems, electronic healthcare records, clinical narratives, literature, and social media: a careful automation on collection, processing and analysis of these data is a current challenge (87). Several Scientific Societies, including the Italian Society of Pharmacology, endorsed the role of RWE

\section{REFERENCES}

1. Lavacchi D, Roviello G, D'Angelo A. Tumor-Agnostic Treatment for Cancer: When How is Better than Where. Clin Drug Investig 2020;40(6):519-27. as an essential element to inform healthcare decisions at the regulatory, clinical and organizational level $(88,89)$. Notwithstanding caveats, including methodological aspects and ethical issues, the role of RWE is expanding to fully complement data from clinical trials across the entire drug life. RWE is useful both in the pre-marketing phases of drug development, providing information on disease burden and unmet clinical needs, as well as in the post-marketing phases, especially monitor drug uptake, investigate prescribing appropriateness, perform comparative effectiveness/safety research, implement and assess and impact of risk minimization measures. The oncological are(n)a, with advanced therapy medicinal products and mutation-driven anticancer drugs, offers an unprecedented opportunity for a bedside RWE. We strongly believe that clinical pharmacologists can play a pivotal role within this multidisciplinary task force embracing RWE and Al in proactively managing patient care, becoming, why not, an asset for the healthcare system to achieve this Mission.

\section{ACKNOWLEDGMENTS}

The authors thank Professor Giorgio Racagni, President of the Italian Society of Pharmacology (SIF), for encouraging the submission of this manuscript. Thanks are also due to Professor Enrico Mini who coordinated the activity of the Cancer Pharmacology Working Group of the SIF.

\section{CONFLICT OF INTERESTS}

The authors declare that they have no conflict of interests.

2. Danesi R, Fogli S, Indraccolo S, et al. Druggable targets meet oncogenic drivers: opportunities and limitations of target-based classification of tumors and the 
role of Molecular Tumor Boards. ESMO Open 2021;6(2):100040.

3. Beaver JA, Pazdur R. "Dangling" Accelerated Approvals in Oncology. $\mathrm{N}$ Engl J Med 2021;384(18):e68.

4. Desnoyers A, Wilson BE, Nadler MB, Amir E. Fragility index of trials supporting approval of anti-cancer drugs in common solid tumours. Cancer Treat Rev 2021;94:102167.

5. Del Paggio JC, Tannock IF. The fragility of phase 3 trials supporting FDA-approved anticancer medicines: a retrospective analysis. Lancet Oncol 2019;20(8):1065-9.

6. Chen EY, Raghunathan V, Prasad V. An Overview of Cancer Drugs Approved by the US Food and Drug Administration Based on the Surrogate End Point of Response Rate. JAMA Intern Med 2019;179(7):915-21.

7. Naci H, Davis C, Savović J, et al. Design characteristics, risk of bias, and reporting of randomised controlled trials supporting approvals of cancer drugs by European Medicines Agency 2014-16: cross sectional analysis. BMJ 2019;366:15221.

8. Gyawali B, Hey SP, Kesselheim AS. Assessment of the Clinical Benefit of Cancer Drugs Receiving Accelerated Approval. JAMA Intern Med 2019;179(7):906-13.

9. Feinberg BA, Gajra A, Zettler ME, Phillips TD, Phillips EG Jr, Kish JK. Use of Real-World Evidence to Support FDA Approval of Oncology Drugs. Value Health 2020;23(10):1358-65.

10. Raphael MJ, Gyawali B, Booth CM. Real-world evidence and regulatory drug approval. Nat Rev Clin Oncol 2020;17(5):271-2.

11. Grisafi D, Ceschi A, Sava G, Avalos Clerici V, Scaglione F. Reconsidering clinical pharmacology frameworks as a necessary strategy for improving the health care of patients: a systematic review. Eur J Clin Pharmacol 2018;74(12):1663-70.

12. Herrmann J. Adverse cardiac effects of cancer therapies: cardiotoxicity and arrhythmia. Nat Rev Cardiol 2020;17(8):474-502.
13. Herrmann J. Vascular toxic effects of cancer therapies. Nat Rev Cardiol 2020;17(8):503-22.

14. Raschi E, Diemberger I, Cosmi B, De Ponti F. ESC position paper on cardiovascular toxicity of cancer treatments: challenges and expectations. Intern Emerg Med 2018;13(1):1-9.

15. Gatti M, Raschi E, Poluzzi E, et al. The Complex Management of Atrial Fibrillation and Cancer in the COVID-19 Era: Drug Interactions, Thromboembolic Risk, and Proarrhythmia. Curr Heart Fail Rep 2020;17(6):365-83.

16. Salem JE, Manouchehri A, Moey M, et al. Cardiovascular toxicities associated with immune checkpoint inhibitors: an observational, retrospective, pharmacovigilance study. Lancet Oncol 2018;19(12):1579-89.

17. D'Souza M, Nielsen D, Svane IM, et al. The risk of cardiac events in patients receiving immune checkpoint inhibitors: a nationwide Danish study. Eur Heart J 2021;42(16):1621-31.

18. Patel NP, Doukas PG, Gordon LI, Akhter N. Cardiovascular Toxicities of CAR T-cell Therapy. Curr Oncol Rep 2021;23(7):78.

19. Raschi E, Mazzarella A, Antonazzo IC, et al. Toxicities with Immune Checkpoint Inhibitors: Emerging Priorities From Disproportionality Analysis of the FDA Adverse Event Reporting System. Target Oncol 2019;14(2):205-21.

20. Reid PD, Cifu AS, Bass AR. Management of Immunotherapy-Related Toxicities in $\mathrm{Pa}$ tients Treated With Immune Checkpoint Inhibitor Therapy. JAMA 2021;325(5):482-3.

21. Raschi E, Gatti M, Gelsomino F, Ardizzoni A, Poluzzi E, De Ponti F. Lessons to be Learnt from Real-World Studies on Immune-Related Adverse Events with Checkpoint Inhibitors: A Clinical Perspective from Pharmacovigilance. Target Oncol 2020;15(4):449-66.

22. Raschi E, La Placa M, Poluzzi E, De Ponti $F$. The value of case reports and spontaneous reporting systems for pharmacovig- 
ilance and clinical practice. $\mathrm{Br} \mathrm{J}$ Dermatol 2021;184(3):581-3.

23. Khouri C, Petit C, Tod M, Lepelley M, Revol B, Roustit M, Cracowski JL. Adverse drug reaction risks obtained from meta-analyses and pharmacovigilance disproportionality analyses are correlated in most cases. J Clin Epidemiol 2021;134:14-21.

24. Raschi E, Moretti U, Salvo F, et al. Evolving Roles of Spontaneous Reporting Systems to Assess and Monitor Drug Safety, Pharmacovigilance, Charmy S. Kothari, Manan Shah and Rajvi Manthan Patel, IntechOpen 2018; Doi: 10.5772/intechopen.79986. Available from https://www.intechopen. com/books/pharmacovigilance/evolvingroles-of-spontaneous-reporting-systemsto-assess-and-monitor-drug-safety.

25. Perez C, Olivier P, Lortal B, et al. Detection of drug safety signals from clinical trials data: Role of SUSARs. Pharmacol Res 2018;131:218-23.

26. Maher RL, Hanlon J, Hajjar ER. Clinical consequences of polypharmacy in elderly. Expert Opin Drug Saf. 2014;13(1):57-65.

27. Valderas JM, Starfield B, Sibbald B, Salisbury C, Roland M. Defining comorbidity: implications for understanding health and health services. Ann Fam Med 2009;7(4):357-63.

28. Wastesson JW, Morin L, Tan ECK, Johnell $\mathrm{K}$. An update on the clinical consequences of polypharmacy in older adults: a narrative review. Expert Opin Drug Saf 2018;17(12):1185-96.

29. Johnell K, Klarin I. The relationship between number of drugs and potential drug-drug interactions in the elderly: a study of over 600,000 elderly patients from the Swedish Prescribed Drug Register Drug Saf 2007;30(10):911-8.

30. Köhler GI, Bode-Böger SM, Busse R, Hoopmann M, Welte T, Böger RH. Drugdrug interactions in medical patients: effects of in-hospital treatment and relation to multiple drug use. Int J Clin Pharmacol Ther 2000;38(11):504-13.
31. Alnaim L. Therapeutic drug monitoring of cancer chemotherapy. J Oncol Pharm Pract 2007;13(4):207-21.

32. Thomas-Schoemann A, Blanchet B, Bar$\operatorname{din} C$, et al. Drug interactions with solid tumour-targeted therapies. Crit Rev Oncol Hematol 2014;89(1):179-96.

33. König J, Müller F, Fromm MF. Transporters and drug-drug interactions: important determinants of drug disposition and effects. Pharmacol Rev 2013;65(3):944-66.

34. Baena-Cañada JM, Martínez MJ, García-Olmedo $O$, Jiménez-Bárcenas $R$, Muriel-Cueto $P$. Interaction between capecitabine and brivudin in a patient with breast cancer. Nat Rev Clin Oncol 2010;7(1):55-8.

35. Rätz Bravo $A E$, Hofer $S$, Krähenbühl $S$, Ludwig C. Fatal drug-drug interaction of brivudine and capecitabine. Acta Oncol 2009;48(4):631-3.

36. Available from https://www.aifa.gov.it/-/ nota-informativa-importante-sui-medicinali-a-base-di-brivudina-02-08-2012.

37. Crestan D, Trojniak MP, Francescon S, Fornasier G, Baldo P. Pharmacovigilance of anti-cancer medicines: opportunities and challenges. Expert Opin Drug Saf 2020;19(7):849-60.

38. van Leeuwen RWF, Jansman FGA, van den Bemt PMLA, et al. Drug-drug interactions in patients treated for cancer: a prospective study on clinical interventions. Ann Oncol 2015;26(5):992-7.

39. Tascilar M, de Jong FA, Verweij J, Mathijssen $\mathrm{RH}$. Complementary and alternative medicine during cancer treatment: beyond innocence. Oncologist 2006;11(7):732-41.

40. Ben-Arye E, Samuels N, Goldstein LH, et al. Potential risks associated with traditional herbal medicine use in cancer care: A study of Middle Eastern oncology health care professionals. Cancer 2016;122(4):598-610.

41. Gougis P, Hilmi M, Geraud A, Mir O, Funck-Brentano C. Potential Cytochrome P450-mediated pharmacokinetic interactions between herbs, food, and dietary 
supplements and cancer treatments. Crit Rev Oncol Hematol 2021:103342.

42. lacuzzi V, Posocco B, Zanchetta M, et al. Development and validation of LC-MS/MS method for imatinib and norimatinib monitoring by finger-prick DBS in gastrointestinal stromal tumor patients. PLoS One. 2019;14(11):e0225225.

43. Fung EN, Bryan P, Kozhich A. Techniques for quantitative LC-MS/MS analysis of protein therapeutics: advances in enzyme digestion and immunocapture. Bioanalysis 2016;8(8):847-56.

44. Tsunoda SM, Gonzales C, Jarmusch AK, Momper JD, Ma JD. Contribution of the Gut Microbiome to Drug Disposition, Pharmacokinetic and Pharmacodynamic Variability. Clin Pharmacokinet 2021. Doi: 10.1007/s40262-021-01032-y. Epub ahead of print. PMID: 33959897.

45. Uchiyama AAT, Silva PAIA, Lopes MSM, Yen CT, Ricardo ED, Mutão T, Pimenta JR, Machado LM, Shimba DS, Peixoto RD. Proton Pump Inhibitors and Oncologic Treatment Efficacy: A Practical Review of the Literature for Oncologists. Curr Oncol 2021;28(1):783-99.

46. Johnson JA. Pharmacogenetics: potential for individualized drug therapy through genetics. Trends Genet 2003;19(11):660-6.

47. Becquemont L. Pharmacogenomics of adverse drug reactions: practical applications and perspectives. Pharmacogenomics 2009;10(6):961-9.

48. Nagy M, Attya M, Patrinos GP. Unraveling heterogeneity of the clinical pharmacogenomic guidelines in oncology practice among major regulatory bodies. Pharmacogenomics 2020;21(17):1247-64.

49. Schmoll HJ, Cartwright T, Tabernero J, et al. Phase III trial of capecitabine plus oxaliplatin as adjuvant therapy for stage III colon cancer: a planned safety analysis in 1,864 patients. J Clin Oncol 2007;25(1):102-9.

50. Meta-Analysis Group In Cancer, Lévy E, Piedbois $\mathrm{P}$, et al. Toxicity of fluorouracil in patients with advanced colorectal cancer: effect of administration schedule and prognostic factors. J Clin Oncol 1998;16(11):3537-41.

51. Henricks LM, van Merendonk LN, Meulendijks $D$, et al. Effectiveness and safety of reduced-dose fluoropyrimidine therapy in patients carrying the DPYD* $2 A$ variant: A matched pair analysis. Int J Cancer 2019;144(9):2347-54.

52. Del Re M, Quaquarini E, Sottotetti F, et al. Uncommon dihydropyrimidine dehydrogenase mutations and toxicity by fluoropyrimidines: a lethal case with a new variant. Pharmacogenomics 2016;17(1):5-9.

53. Terrazzino S, Cargnin S, Del Re M, Danesi $R$, Canonico PL, Genazzani AA. DPYD IVS14+1G > A and 2846A > T genotyping for the prediction of severe fluoropyrimidine-related toxicity: a meta-analysis. Pharmacogenomics 2013;14(11):1255-72.

54. Available from https://www.ema.europa.eu/en/news/ema-recommendations-dpd-testing-prior-treatment-fluorouracil-capecitabine-tegafur-flucytosine.

55. Available from https://sif-website.s3.amazonaws.com/uploads/document/attachment/155/2019_Racc-analisi-farmacogenetiche_v26.3.2020.pdf.

56. Caudle KE, Klein TE, Hoffman JM, et al. Incorporation of pharmacogenomics into routine clinical practice: the Clinical Pharmacogenetics Implementation Consortium (CPIC) guideline development process. Curr Drug Metab 2014;15(2):209-17.

57. Lunenburg CATC, van der Wouden $\mathrm{CH}$, Nijenhuis $\mathrm{M}$, et al. Dutch Pharmacogenetics Working Group (DPWG) guideline for the gene-drug interaction of DPYD and fluoropyrimidines. Eur J Hum Genet 2020;28(4):508-17.

58. Pasternak AL, Ward KM, Luzum JA, Ellingrod VL, Hertz DL. Germline genetic variants with implications for disease risk and therapeutic outcomes. Physiol Genomics 2017;49(10):567-81.

59. Barbarino JM, Haidar CE, Klein TE, Altman RB. PharmGKB summary: very im- 
portant pharmacogene information for UGT1A1. Pharmacogenet Genomics 2014;24(3):177-83.

60. The Royal Dutch Pharmacists Association Pharmacogenetics Working Group. DPWG Guideline for irinotecan and UGT1A1. Available from https://www.pharmgkb. org/guidelineAnnotation/PA166104951.

61. Available from: https://sif-website.s3.amazonaws.com/uploads/document/attachment/155/2019_Racc-analisi-farmacogenetiche_v26.3.2020.pdf.

62. Available from https://upgx.eu/.

63. Cecchin E, Roncato R, Guchelaar HJ, Toffoli G. Ubiquitous Pharmacogenomics Consortium. Ubiquitous Pharmacogenomics (U-PGx): The Time for Implementation is Now. An Horizon2020 Program to Drive Pharmacogenomics into Clinical Practice. Curr Pharm Biotechnol 2017;18(3):204-9.

64. Hughes $T$, Deininger $M$, Hochhaus $A$, et al. Monitoring $\mathrm{CML}$ patients responding to treatment with tyrosine kinase inhibitors: review and recommendations for harmonizing current methodology for detecting BCR-ABL transcripts and kinase domain mutations and for expressing results. Blood 2006;108(1):28-37.

65. Gao B, Yeap S, Clements A, Balakrishnar $B$, Wong $M$, Gurney $H$. Evidence for therapeutic drug monitoring of targeted anticancer therapies. J Clin Oncol 2012;30(32):4017-25.

66. Saleem M, Dimeski G, Kirkpatrick CM, Taylor PJ, Martin JH. Target concentration intervention in oncology: where are we at? Ther Drug Monit 2012;34(3):257-65.

67. Beumer JH. Without therapeutic drug monitoring, there is no personalized cancer care. Clin Pharmacol Ther 2013;93(3):228-30.

68. Baccarani M, Dreyling M, ESMO Guidelines Working Group. Chronic myeloid leukaemia: ESMO Clinical Practice Guidelines for diagnosis, treatment and follow-up. Ann Oncol 2010;21 Suppl 5:v165-7.

69. von Mehren M, Widmer N. Correlations between imatinib pharmacokinetics, phar- macodynamics, adherence, and clinical response in advanced metastatic gastrointestinal stromal tumor (GIST): an emerging role for drug blood level testing? Cancer Treat Rev 2011;37(4):291-9.

70. Widmer N, Bardin C, Chatelut E, et al. Review of therapeutic drug monitoring of anticancer drugs part two--targeted therapies. Eur J Cancer 2014;50(12):2020-36.

71. Verheijen RB, Yu H, Schellens JHM, Beijnen JH, Steeghs $N$, Huitema ADR. Practical Recommendations for Therapeutic Drug Monitoring of Kinase Inhibitors in Oncology. Clin Pharmacol Ther 2017;102(5):765-76.

72. van Eerden, RAG, Oomen-de Hoop E, Noordam, A, Mathijssen RHJ, Koolen SLW. Feasibility of Extrapolating Randomly Taken Plasma Samples to Trough Levels for Therapeutic Drug Monitoring Purposes of Small Molecule Kinase Inhibitors. Pharmaceuticals 2021;14:119.

73. Weber J. Immunotherapy for melanoma. Curr Opin Oncol 2011;23(2):163-9.

74. Borghaei $H$, Paz-Ares L, Horn $L$, et al. Nivolumab versus docetaxel in advanced nonsquamous non-small-cell lung cancer. N Engl J Med 2015;373:1627-1639.

75. Zhang Y, Zhang Z. The history and advances in cancer immunotherapy: understanding the characteristics of tumor-infiltrating immune cells and their therapeutic implications. Cell Mol Immunol 2020;17(8):807-21.

76. Centanni M, Moes DJAR, Trocóniz IF, Ciccolini J, van Hasselt JGC. Clinical Pharmacokinetics and Pharmacodynamics of Immune Checkpoint Inhibitors. Clin Pharmacokinet 2019;58(7):835-57.

77. Topalian SL, Drake CG, Pardoll DM. Immune checkpoint blockade: a common denominator approach to cancer therapy. Cancer Cell 2015;27(4):450-61.

78. Siu LL, Ivy SP, Dixon EL, Gravell AE, Reeves SA, Rosner GL. Challenges and Opportunities in Adapting Clinical Trial Design for Immunotherapies. Clin Cancer Res 2017;23(17):4950-8. 
79. Chatterjee MS, Elassaiss-Schaap J, Lindauer $\mathrm{A}$, et al. Population phSarmacokinetic/pharmacodynamic modeling of tumor size dynamics in pembrolizumab-treated advanced melanoma. CPT Pharmacomet Syst Pharmacol 2017;6:29-39.

80. Wang X, Feng Y, Bajaj G, et al. Quantitative characterization of the exposure-response relationship for cancer immunotherapy: a case study of nivolumab in patients with advanced melanoma. CPT Pharmacomet Syst Pharmacol 2017;6:40-4.

81. Feng $Y$, Roy A, Masson E, Chen TT, Humphrey R, Weber JS. Exposure-response relationships of the efficacy and safety of ipilimumab in patients with advanced melanoma. Clin Cancer Res 2013;19(14):3977-86.

82. Chiu HH, Liao HW, Shao YY, et al. Development of a general method for quantifying IgG-based therapeutic monoclonal antibodies in human plasma using protein $G$ purification coupled with a two internal standard calibration strategy using LC-MS/ MS. Anal Chim Acta 2018;1019:93-102.

83. Basak EA, Wijkhuijs AJM, Mathijssen RHJ, Koolen SLW, Schreurs MWJ. Development of an Enzyme-Linked Immune Sorbent Assay to Measure Nivolumab and Pembroli- zumab Serum Concentrations. Ther Drug Monit 2018;40(5):596-601.

84. Le Louedec F, Leenhardt F, Marin C, Chatelut É, Evrard A, Ciccolini J. Cancer Immunotherapy Dosing: A Pharmacokinetic/ Pharmacodynamic Perspective. Vaccines (Basel) 2020;8(4):632.

85. Brown DG, Wobst HJ. A Decade of FDA-Approved Drugs (2010-2019): Trends and Future Directions. J Med Chem 2021;64(5):2312-38.

86. Ferrer F, Fanciullino R, Milano G, Ciccolini J. Towards Rational Cancer Therapeutics: Optimizing Dosing, Delivery, Scheduling, and Combinations. Clin Pharmacol Ther 2020;108(3):458-70.

87. Lee CY, Chen YP. Machine learning on adverse drug reactions for pharmacovigilance. Drug Discov Today 2019;24(7):1332-43.

88. Martini N, Trifirò G, Capuano A, et al. Expert opinion on Real-World Evidence (RWE) in drug development and usage. Pharmadvances 2020;2(2):41-50. Doi: 10.36118/pharmadvances.02.2020.01.

89. Sultana J, Addis A, Braga M, et al. What can real-world evidence contribute to regulatory science in pre- and post- marketing setting? Pharmadvances 2020;2(2):51-8. Doi: 10.36118/pharmadvances.02.2020.02.

\section{SUPPLEMENTARY MATERIALS}

Supplementary references published after the Review Article by Raschi et al. Target Oncol. 2020 Aug;15(4):449-466 (as of May 7th, 2021)

1 Allenbach $Y$, Anquetil C, Manouchehri A, et al. Immune checkpoint inhibitor-induced myositis, the earliest and most lethal complication among rheumatic and musculoskeletal toxicities. Autoimmun Rev 2020;19(8):102586. Doi: 10.1016/j.autrev.2020.102586.

2 Anand K, Sahu G, Burns E, et al. Mycobacterial infections due to PD-1 and PD-L1 checkpoint inhibitors. ESMO Open 2020;5(4):e000866. Doi: 10.1136/esmoopen-2020-000866.
3 Anquetil C, Salem JE, Lebrun-Vignes $B$, et al. Evolving spectrum of drug-induced uveitis at the era of immune checkpoint inhibitors results from the WHO's pharmacovigilance database. J Autoimmun 2020;111:102454. Doi: 10.1016/j. jaut.2020.102454.

4 Anthony N, Bourneau-Martin D, Ghamrawi S, Lagarce L, Babin M, Briet M. Drug-induced vitiligo: a case/non-case study in Vigibase ${ }^{\circledR}$, the $\mathrm{WHO}$ pharmacovigi- 
lance database. Fundam Clin Pharmacol 2020;34(6):736-42.

5 Asada M, Mikami T, Niimura T, et al. The Risk Factors Associated with Immune Checkpoint Inhibitor-Related Pneumonitis. Oncology 2021;99(4):256-9.

6 Bai X, Lin X, Zheng K, et al. Mapping endocrine toxicity spectrum of immune checkpoint inhibitors: a disproportionality analysis using the WHO adverse drug reaction database, VigiBase. Endocrine 2020;69(3):670-81.

7 Bai $X$, Chen X, Wu X, et al. Immune checkpoint inhibitor-associated pituitary adverse events: an observational, retrospective, disproportionality study. J Endocrinol Invest 2020;43(10):1473-83.

8 Bastin M, Allouchery M, Sassier M, et al. Characteristics of insulinopenic and non insulinopenic diabetes related to immune checkpoint inhibitors: A French pharmacovigilance study. Therapie 2021;500405957(21)00079-2. Doi: 10.1016/j.therap.2021.03.004.

9 Bomze D, Meirson T, Hasan Ali O, Goldman A, Flatz L, Habot-Wilner Z. Ocular Adverse Events Induced by Immune Checkpoint Inhibitors: A Comprehensive Pharmacovigilance Analysis. Ocul Immunol Inflamm 2020;1-7. Doi: 10.1080/09273948.2020.1773867.

10 Burns EA, Muhsen IN, Anand K, et al. Hepatitis B Virus Reactivation in Cancer Patients Treated With Immune Checkpoint Inhibitors. J Immunother 2021;44(3):132-9.

11 Cautela J, Rouby F, Salem JE, et al. Acute Coronary Syndrome With Immune Checkpoint Inhibitors: A Proof-of-Concept Case and Pharmacovigilance Analysis of a Life-Threatening Adverse Event. Can J Cardiol 2020;36(4):476-481

12 Ceschi A, Noseda R, Palin K, Verhamme K. Immune Checkpoint Inhibitor-Related Cytokine Release Syndrome: Analysis of WHO Global Pharmacovigilance Database. Front Pharmacol 2020;11:557.
13 Chen C, Wu B, Zhang C, Xu T. Immune-related adverse events associated with immune checkpoint inhibitors: An updated comprehensive disproportionality analysis of the FDA adverse event reporting system. Int Immunopharmacol 2021;95:107498. Doi: 10.1016/j.intimp.2021.107498.

14 Chen C, Chen T, Liang J, et al. Cardiotoxicity Induced by Immune Checkpoint Inhibitors: A Pharmacovigilance Study From 2014 to 2019 Based on FAERS. Front Pharmacol 2021;12:616505.

15 Chen G, Qin Y, Fan QQ, Zhao B, Mei D, Li $X M$. Renal adverse effects following the use of different immune checkpoint inhibitor regimens: A real-world pharmacoepidemiology study of post-marketing surveillance data. Cancer Med 2020;9(18):6576-85.

16 Cohen Aubart F, Lhote R, Amoura A, et al. Drug-induced sarcoidosis: an overview of the WHO pharmacovigilance database. J Intern Med 2020;288(3):356-62.

17 Cutroneo $P$, Ingrasciotta $Y$, Isgrò $V$, et al. Psoriasis and psoriasiform reactions secondary to immune checkpoint inhibitors. Dermatol Ther 2021;34(2):e14830.

18 Cutroneo PM, Isgrò V, lentile V, et al. Safety profile of immune checkpoint inhibitors: An analysis of the Italian spontaneous reporting system database. $\mathrm{Br} \mathrm{J}$ Clin Pharmacol 2021;87(2):527-41.

19 Dolladille C, Ederhy S, Sassier M, et al. Immune Checkpoint Inhibitor Rechallenge After Immune-Related Adverse Events in Patients With Cancer. JAMA Oncol 2020 ;6(6):865-71.

20 Fan Q, Hu Y, Wang X, Zhao B. Guillain-Barré syndrome in patients treated with immune checkpoint inhibitors. J Neurol. 2021. Doi: 10.1007/s00415-021-10404-0.

21 Filippini DM, Gatti M, Di Martino V, et al. Bone fracture as a novel immune-related adverse event with immune checkpoint inhibitors: Case series and large-scale pharmacovigilance analysis. Int J Cancer 2021. Doi: 10.1002/ijc.33592. 
22 Gatti M, Raschi E, Moretti U, Ardizzoni A, Poluzzi E, Diemberger I. Influenza Vaccination and Myo-Pericarditis in Patients Receiving Immune Checkpoint Inhibitors: Investigating the Likelihood of Interaction through the Vaccine Adverse Event Reporting System and VigiBase. Vaccines (Basel) 2021;9(1):19. Doi: 10.3390/vaccines 9010019.

23 Grouthier V, Lebrun-Vignes B, Moey M, et al. Immune Checkpoint Inhibitor-Associated Primary Adrenal Insufficiency: WHO VigiBase Report Analysis. Oncologist 2020;25(8):696-701.

24 Hasegawa S, Ikesue H, Nakao S, et al. Analysis of immune-related adverse events caused by immune checkpoint inhibitors using the Japanese Adverse Drug Event Report database. Pharmacoepidemiol Drug Saf 2020;29(10):1279-94.

$25 \mathrm{Hu} \mathrm{F}$, Ye X, Zhai Y, et al. Ear and labyrinth toxicities induced by immune checkpoint inhibitors: a disproportionality analysis from 2014 to 2019. Immunotherapy 2020;12(7):531-40.

26 Hu Y, Gong J, Zhang L, et al. Colitis following the use of immune checkpoint inhibitors: A real-world analysis of spontaneous reports submitted to the FDA adverse event reporting system. Int Immunopharmacol 2020;84:106601. Doi: 10.1016/j.intimp.2020.106601.

27 Huang S, Bai X, Fang T, Guo Y, Zheng K, Lin $X$. Gastrointestinal toxicities associated with immune checkpoint inhibitors: a disproportionality analysis leveraging VigiBase, the WHO Adverse Drug Reaction Database. J Zhejiang Univ Sci B 2021;22(2):156-64.

28 Kerepesi C, Bakacs T, Moss RW, Slavin S, Anderson CC. Significant association between tumor mutational burden and immune-related adverse events during immune checkpoint inhibition therapies. Cancer Immunol Immunother 2020;69(5):683-7.

29 Ma R, Wang Q, Meng D, Li K, Zhang Y. Immune checkpoint inhibitors-related myo- carditis in patients with cancer: an analysis of international spontaneous reporting systems. BMC Cancer 2021;21(1):38.

30 Mikami T, Liaw B, Asada M, et al. Neuroimmunological adverse events associated with immune checkpoint inhibitor: a retrospective, pharmacovigilance study using FAERS database. J Neurooncol 2021;152(1):135-44.

31 Nguyen LS, Ortuno S, Lebrun-Vignes B, et al. Transplant rejections associated with immune checkpoint inhibitors: A pharmacovigilance study and systematic literature review. Eur J Cancer 2021;148:36-47.

32 Nguyen LS, Raia L, Lebrun-Vignes B, Salem JE. Graft Versus Host Disease Associated with Immune Checkpoint Inhibitors: A Pharmacovigilance Study and Systematic Literature Review. Front Pharmacol 2021;11:619649.

33 Noseda R, Bonaldo G, Motola D, Stathis A, Ceschi A. Adverse Event Reporting with Immune Checkpoint Inhibitors in Older Patients: Age Subgroup Disproportionality Analysis in VigiBase. Cancers (Basel) 2021;13(5):1131.

34 Noseda R, Ruinelli L, Gaag LCV, Ceschi A. Pre-Existing Cardiovascular Conditions as Clinical Predictors of Myocarditis Reporting with Immune Checkpoint Inhibitors: A VigiBase Study. Cancers (Basel) 2020;12(11):3480.

35 Picca A, Berzero G, Bihan K, et al. Longitudinally Extensive Myelitis Associated With Immune Checkpoint Inhibitors. Neurol Neuroimmunol Neuroinflamm 2021;8(3):e967.

36 Pujalte-Martin M, Rocher F, Cardot-Leccia N, Giacchero D, Borchiellini D. Immune checkpoint inhibitor-induced bullous pemphigoid: Towards a new class of drug-drug interaction? Eur J Cancer 2020;138:122-4.

37 Reese SW, Marchese M, McNabb-Baltar J. Insights from Pharmacovigilance: Gastrointestinal-Related Immune Checkpoint Inhibitor Adverse Events. Gastroenterology 2020;159(4):1195-1200.e1. 
38 Reese SW, Cone E, Marchese $\mathrm{M}$, et al. Lessons from Pharmacovigilance: Pulmonary Immune-Related Adverse Events After Immune Checkpoint Inhibitor Therapy. Lung 2021;199(2):199-211.

39 Ruggiero R, Fraenza F, Scavone C, et al. Immune Checkpoint Inhibitors and Immune-Related Adverse Drug Reactions: Data From Italian Pharmacovigilance Database. Front Pharmacol 2020 Jun 9;11:830.

40 Saberianfar S, Nguyen LS, Manouchehri A, et al. Solid organ transplant rejection associated with immune-checkpoint inhibitors. Ann Oncol 2020;31(4):543-4.

41 Scanvion Q, Béné J, Gautier S, et al. Moderate-to-severe eosinophilia induced by treatment with immune checkpoint inhibitors: 37 cases from a national reference center for hypereosinophilic syndromes and the French pharmacovigilance database. Oncoimmunology 2020;9(1):1722022. Doi: 10.1080/2162402X.2020.1722022.

42 Schaefer A, Sachpekidis C, Diella F, et al. Public Adverse Event Data Insights into the Safety of Pembrolizumab in Melanoma Patients. Cancers (Basel) 2020;12(4):1008.

43 Shah KP, Song H, Ye F, et al. Demographic Factors Associated with Toxicity in $\mathrm{Pa}$ - tients Treated with Anti-Programmed Cell Death-1 Therapy. Cancer Immunol Res 2020;8(7):851-5.

44 Terrier B, Humbert S, Preta LH, et al. Risk of scleroderma according to the type of immune checkpoint inhibitors. Autoimmun Rev 2020;19(8):102596. Doi: 10.1016/j.autrev.2020.102596.

45 Vartanov A, Kalotra A, Varughese J, Gautam S, Kandel S, Hosmer W. Immunotherapy-associated complete heart block in a patient with NSCLC: A case report and literature review. Respir Med Case Rep. 2021;33:101390.

46 Jing $Y$, Zhang $Y$, Wang J, et al. Association Between Sex and Immune-Related Adverse Events During Immune Checkpoint Inhibitor Therapy. J Natl Cancer Inst 2021:djab035.

47 Jing Y, Liu J, Ye Y, et al. Multi-omics prediction of immune-related adverse events during checkpoint immunotherapy. Nat Commun 2020;11(1):4946.

$48 \mathrm{Ye} \mathrm{X}$, Hu F, Zhai $Y$, et al. Hematological toxicities in immune checkpoint inhibitors: A pharmacovigilance study from 2014 to 2019. Hematol Oncol 2020;38(4):565-75. 